\title{
For Immediate Release
}

Contacts:

Ad Hoc Group for Medical Research -- Dave Moore 202-828-0559

Campaign for Medical Research - Nancy Granese 202-637-2865

Federation of American Societies for Experimental Biology

(FASEB) - Carrie D. Wolinetz, Ph.D. 301-634-7650

National Health Council - Kevin Cain 202-973-0542

Research!America - Heather Jameson 703-739-2577, ext. 20

\section{Major Medical Research Coalitions Urge Congress to Accelerate Medical Progress by Increasing Investment in NIH}

WASHINGTON, Feb. 28 -- Health research advocates joined together to call on Congress to expand the nation's investment in medical research by increasing the budget of the National Institutes of Health (NIH) by $\$ 1.9$ billion in Fiscal Year (FY) 2009.

Five eminent medical research advocacy groups -- the Ad Hoc Group for Medical Research, the Campaign for Medical Research (CMR), the Federation of American Societies for Experimental Biology (FASEB), the National Health Council (NHC), and Research!America -- also criticized the Bush Administration's proposal to freeze funding for the NIH at the current year's level.

The groups note that the Administration's request of $\$ 29.2$ billion for $\mathrm{NIH}$ in FY 2009 represents the sixth consecutive year that the President's proposed budget for the NIH has failed to keep pace with biomedical inflation. In that period, a combination of nominal increases and cuts has amounted to flat funding for $\mathrm{NIH}$, resulting in an approximately $11 \%$ decline in the agency's purchasing power due to inflation. If the President's FY 2009 request becomes law, NIH will have lost nearly $14 \%$ of its purchasing power due to inflation

The advocacy groups' recommendation would increase NIH's budget by $6.6 \%$, halting this erosion of the nation's medical research effort, and permit the world's pre-eminent research enterprise to accelerate the momentum of discovery to improve the health and quality of life for millions of Americans.

"Although President Bush has given lip-service to supporting the search for treatment for diseases like cancer, Alzheimer's and pandemic influenza, this budget again reveals his failure to uphold that commitment," said Robert Palazzo, Ph.D., FASEB President. "This is an injustice to the patients and their families suffering from conditions for which research funded by $\mathrm{NIH}$ is their only hope." 
"NIH-funded research is driving the transformation of the practice of medicine. At a time of unparalleled scientific opportunities and unprecedented health challenges, NIH must be given the resources to continue to move forward, not stand in place," stated Richard M. Knapp, Ph.D., chair of the Ad Hoc Group.

"The health needs of the aging Baby Boomer generation have the potential to bankrupt the US healthcare system and sap the nation's future economic growth. Investment in medical research is key to delaying the onset of the chronic and costly diseases that affect the elderly," said G. Steven Burrill, CMR chair. "While research holds the key to new treatments, prevention strategies, and cures, this Administration refuses to allocate resources to build on promising breakthrough research that offers hope to our families and our children."

"Secure, consistent funding for health and scientific research must be part of the nation's long-term strategies for sustained economic growth. Investment in cutting-edge research ensures that the U.S. will continue to lead the world in scientific breakthroughs and fuels our economic growth and productivity," said Mary Woolley, president of Research!America. "This disappointing budget undermines the President's own efforts to make our nation more competitive in the global marketplace. It also ignores the expressed views of the American public. A majority of Americans want increased funding for our federal health research agencies, according to national polls commissioned by Research!America."

"Saving a little money today makes no sense when the price we pay tomorrow will surely be much higher in terms of lives that could have been saved and the loss of our competitive edge in medical research," said Myrl Weinberg, NHC President. "Let's continue our investment in NIH and not impede American innovation."

To sustain a national commitment to research and fighting disease, the Ad Hoc Group, the Campaign for Medical Research, FASEB, the National Health Council and Research!America urge the Administration and Congress to work to increase the investment in the life-saving medical research the American people want and deserve.

\section{\# \# \#}

The Ad Hoc Group for Medical Research, the Campaign for Medical Research, FASEB, the National Health Council, and Research!America include more than 500 patient groups, scientific and professional societies, research and academic institutions, and industry that represent more than 125 million Americans. 